\title{
AVALIAÇÃO DA EFICIÊNCIA DE UM SISTEMA DE TRATAMENTO MULTIFUNCIONAL DE BAIXO CUSTO PARA TRATAMENTO DE ÁGUAS RESIDUAIS HOSPITALARES, ATRAVÉS DE ENSAIOS ECOTOXICOLÓGICOS, SANTA CRUZ DO SUL, RS, BRASIL
}

\author{
OLIVEIRA, S.1 ; RIBEIRO, V. R. ${ }^{2}$; DÜPONT, A. ${ }^{3}$; LUTTERBECK, C. A. E.4; MACHADO, Ê. L.4; LOBO, E. A.4*
}

PALAVRAS-CHAVE: Lavanderia Hospitalar. Wetlands Construídos. Célula de Combustível Microbiana. Ecotoxicologia.

\begin{abstract}
RESUMO
Atividades humanas, como a descarga de qualquer tipo de efluente em sistemas lóticos e lênticos, geralmente sem nenhum tipo de tratamento, estão atualmente se tornando uma das principais preocupações ambientais. Por exemplo, efluentes de lavanderia hospitalar são caracterizados como tendo alto impacto ambiental entre os setores das unidades de saúde. Dessa forma, sistemas integrados de tratamento de efluentes têm sido propostos para melhorar sua eficiência. Neste contexto, esta pesquisa teve como objetivo avaliar a eficiência de um sistema de tratamento multifuncional de baixo custo, integrando o uso de uma célula de combustível microbiana (CCM) com Wetland Construído de Fluxo Vertical (WCFV), para o tratamento de resíduos da lavanderia do Hospital Santa Cruz, Município de Santa Cruz do Sul, RS, Brasil. Os ensaios ecotoxicológicos agudos consistiram em expor o organismo bioindicador Daphnia magna por 48 horas a diferentes concentrações do efluente testado, verificando sua mortalidade e/ou imobilidade. Os resultados indicaram que P1, ponto de coleta correspondente ao efluente bruto, apresentou uma toxicidade aguda média de $\mathrm{CE}(\mathrm{I}) 50 \quad 48 \mathrm{~h} \%=29,3 \pm$ $15,5 \%$ (Coeficiente de Variação, $C V=52,8 \%$ ), sendo classificado como altamente tóxico. Já P2, ponto de coleta correspondente ao efluente tratado, apresentou uma toxicidade aguda média de $\operatorname{CE}(\mathrm{I}) 5048 \mathrm{~h} \%=100,0 \pm 0,0 \%$, sendo classificado como não tóxico. Concluímos, desta forma, que o sistema de tratamento multifuncional de baixo custo para remediação de efluentes de lavanderia hospitalar, foi altamente eficiente, uma vez que houve a completa detoxificação do mesmo, representando uma alternativa promissora para a remoção de toxicidade de efluentes hospitalares.
\end{abstract}

\section{EVALUATION OF THE EFFICIENCY OF A LOW COST MULTIFUNCTIONAL TREATMENT SYSTEM FOR HOSPITAL LAUNDRY WASTEWATER TREATMENT, THROUGH ECOTOXICOLOGICAL TESTS, SANTA CRUZ DO SUL, RS, BRAZIL}

KEYWORDS: Hospital Laundry. Constructed Wetlands. Microbial Fuel Cell. Ecotoxicology.

\begin{abstract}
Human activities such as the discharge of any kind of effluents in lotic and lentic systems, generally without any type of treatment, are currently becoming one of the main environmental concerns. For example, hospital laundry effluents are characterized as having a high environmental impact among the health unit sectors. In this way, integrated systems for the treatment of effluents have been proposed in order to improve their efficiency. In this context, this research aimed at evaluating the efficiency of a low cost multifunctional treatment system, integrating the use of a Microbial Fuel Cell (MFC) with Vertical Flow Constructed Wetland (VFCW) for wastewater treatment from the Santa Cruz Hospital laundry, Municipality of Santa Cruz do Sul, RS, Brazil. The acute ecotoxicological tests consisted of exposing the bioindicator organism Daphnia magna for 48 hours to different concentrations of the tested effluent, checking its mortality and/or immobility. The results indicated that P1, the sampling site corresponding to the raw effluent, presented an average acute toxicity of EC(I)50 $48 \mathrm{~h} \%=$ $29.3 \pm 15.5 \%$ (Coefficient of Variation, CV $=52.8 \%$ ), being classified as highly toxic. P2, the sampling site corresponding to the treated effluent, presented an average acute toxicity of EC(I)50 $48 \mathrm{~h} \%=100.0 \pm 0.0 \%$, being

1 Acadêmica do curso de Ciências Biológicas na Universidade de Santa Cruz do Sul (UNISC). E-mail: samanta1@mx2.unisc.br
2 Bióloga e Discente do Curso de Mestrado em Tecnologia Ambiental da UNISC (PPGTA/UNISC). E-mail: vanessa.rrib@hotmail.com
${ }^{3}$ Bióloga, Mestre em Tecnologia Ambiental e responsável pelo Laboratório de Ecotoxicologia da UNISC. E-mail: $\underline{\text { adrianad@unisc.br }}$

${ }^{4}$ Doutor, pesquisador do PPGTA/UNISC. E-mail: carlosalexandre@unisc.br (Lutterbeck), enio@unisc.br (Machado), lobo@unisc.br* (Lobo*)
\end{abstract}


classified as non-toxic. We concluded, therefore, that the low cost multifunctional treatment system for hospital laundry effluents remediation was highly efficient, since it was completely detoxified, representing a promising alternative for removing toxicity from hospital effluents.

\section{INTRODUÇÃO}

Atividades humanas correspondem à principal fonte poluidora que compromete a qualidade da água no meio ambiente, com destaque para o despejo de esgotos domésticos e/ou industriais em sistemas lóticos e lênticos, em geral sem qualquer tipo de tratamento; sendo que este tema vem se tornando uma das principais preocupações e fórum de discussões nos dias de hoje.

Na natureza existe um sistema de autodepuração que é capaz de decompor a matéria orgânica liberada em seu meio terrestre e hídrico. Entretanto, a abundância de efluentes contendo grande quantidade de material orgânico e químico liberado nos corpos hídricos satura este sistema natural de depuração, tornando-o ineficaz, sendo que este quadro tende a se agravar com o adensamento das cidades, onde a lógica tradicional de ocupação é não possuir uma preocupação em preservar os recursos naturais.

Devido à nocividade ambiental, efluentes de lavanderias hospitalares caracterizam-se como de alto impacto ambiental dentre os setores de uma unidade hospitalar, necessitando de sistemas eficientes de tratamento. Neste sentido, sistemas integrados para tratamento de efluentes têm sido propostos objetivando uma melhor eficiência quanto à qualidade do efluente, visando a recuperação de energia, nutrientes, áreas degradadas e reutilização de água, podendo destacar o uso de wetlands construídos (WC's), onde estes sistemas imitam os alagados/banhados encontrados naturalmente no ambiente. E para o monitoramento da eficiência destes alagados construídos, utilizam-se ferramentas da ecotoxicologia, uma moderna ciência que visa avaliar a toxicidade destes efluentes, onde são utilizados organismos bioindicadores de diferentes níveis tróficos. 0 microcrustáceo Daphnia magna Straus, 1820 (Branchiopoda, Cladocera), destaca-se como um organismo bioindicador que vem sendo amplamente utilizado como organismo-teste em vários experimentos ecotoxicológicos.

Neste contexto, a presente pesquisa teve como objetivo avaliar a eficiência de um sistema de tratamento multifuncional de baixo custo, integrando o uso de célula de combustível microbiana (CCM) e sistema de Wetland construído (WC), para remediação de efluentes provenientes da lavanderia do Hospital Santa Cruz, Santa Cruz do Sul, RS, Brasil, através de ensaios ecotoxicológicos.

\section{FUNDAMENTAÇÃO TEÓRICA}

O descarte inapropriado de efluentes industriais e águas residuais no meio ambiente destaca-se como um dos principais problemas ambientais atualmente, tornando-se imprescindível o desenvolvimento de tecnologias ecologicamente corretas e economicamente viáveis para tratamento destes efluentes. Os primeiros ambientes a sofrerem as consequências do aumento populacional são os corpos hídricos situados próximos aos perímetros urbanos. Estes foram transformados em receptores e diluidores de cargas orgânicas oriundas das atividades humanas, contudo, a grande maioria dessas cargas poluidoras tem sido lançadas sem tratamento, representando riscos potenciais à saúde humana, deteriorando a qualidade de vida (MOTA, 2000; ARAÚJO, 2016). 
Dentre as atividades industriais que merecem destaque em relação ao impacto ambiental sobre os corpos hídricos e à saúde púbica estão as unidades de saúde, uma vez que as águas residuais geradas descarregam substâncias químicas tóxicas que afetam várias espécies aquáticas, incluindo o homem (PAZ et al., 2006; ARAÚJO, 2016). Comparando as diferentes áreas hospitalares, as lavanderias requerem atenção especial devido ao consumo significativo de água e consequente geração de grandes volumes de águas residuais. São efluentes altamente complexos com alta Demanda Química de Oxigênio (DQO) e Demanda Bioquímica de Oxigênio (DBO), alta carga microbiana e toxicidade, bem como altas concentrações de material particulado, gordura, óleos e graxas, detergentes, desinfetantes e produtos farmacêuticos (MACHADO et al., 2012; KERN et al., 2015). Para este propósito, sistemas integrados para tratamento de efluentes têm sido propostos, destacando o uso de células de combustível microbiana (CCM's) e alagados construídos, também chamados de wetlands construídos (WC's).

As CCM's correspondem a um biorreator que utiliza bactérias para oxidar materiais orgânicos e inorgânicos, onde consequentemente ocorre a produção de bioeletricidade e tratamento de águas residuais, simultaneamente, incluindo águas residuais hospitalares (GUDE, 2016; Vo et al., 2019). Já os WC's são sistemas artificiais que simulam e maximizam as condições naturais de áreas alagadas, utilizando macrófitas aquáticas, podendo ser tratados como reatores biológicos (DUNBABIN; BOWMER, 1992). Aplicam-se no tratamento de efluente e águas contaminadas visando a recuperação de nutrientes, além de permitir a reutilização dos mesmos como fertilizantes ou alimentação de animais (SHILTON et al., 2012). Atualmente, grande porção das pesquisas sobre o tema concentram-se nas regiões sul e sudeste, destacando-se os estados de Minas Gerais, Santa Catarina e São Paulo, com maior aplicação no tratamento de esgoto doméstico (MACHADO et al., 2016).

A ecotoxicologia é a moderna ciência que estuda o impacto potencialmente deletério de substâncias ou compostos químicos que constituem poluentes ambientais sobre os organismos vivos, visando avaliar a toxicidade de poluentes em laboratório e no meio ambiente, compreender os mecanismos de ação de substâncias tóxicas e avaliar o risco que substâncias ou compostos químicos tóxicos apresentam para o meio ambiente (BELDEN, 2020; BRENTANO; LOBO, 2003). Ainda, autores discutem que a Ecotoxicologia Aquática é uma ciência que surgiu para dar suporte no enfrentamento dos problemas de contaminação dos corpos d'agua por compostos tóxicos. Seus instrumentos de análise são capazes de responder preditivamente à toxicidade de compostos químicos, sinalizando os potenciais toxicológicos e seus mecanismos de ação em organismos vivos (BELDEN, 2020; LOPES et al., 2020).

Dentre os testes ecotoxicológicos, os ensaios agudos são amplamente difundidos com o microcrustáceo Daphnia magna, conforme descreve a NBR 12713 (ABNT, 2016). A utilização de bioindicadores é extremamente útil, especialmente para a avaliação de impactos ambientais decorrentes de descargas pontuais de esgotos domésticos e efluentes industriais, inclusive para pesticidas (CALLISTO et al., 2005; LOBO et al., 2014; 2016; RAYMUNDO et al., 2019).

Consciente dessa problemática, a Universidade de Santa Cruz do Sul (UNISC) instalou em suas dependências uma Estação de Tratamento de Efluentes (ETE-UNISC), a fim de remover a matéria orgânica e nutrientes proveniente do esgoto doméstico gerado no campus. Complementar a este sistema convencional foi instalado um sistema de tratamento multifuncional de baixo custo, integrando o uso de células de combustível microbiana (CCM's) e sistema de Wetlands construídos (WC's), visando o tratamento de efluentes industriais. Neste contexto, 
a presente pesquisa avaliou a eficiência da detoxificação deste sistema de tratamento multifuncional de baixo custo para remediação de efluentes provenientes da lavanderia do Hospital Santa Cruz, Santa Cruz do Sul, RS, Brasil, utilizando D. magna como organismo bioindicador.

\section{MATERIAIS E MÉTODOS}

\subsection{Caracterização dos locais de estudo}

O estudo foi realizado na Universidade de Santa Cruz do Sul (UNISC) (figura 1) em conjunto com o Hospital Santa Cruz (HSC), ambos localizados na cidade de Santa Cruz do Sul, RS, Brasil. A universidade tem disposta em suas dependências uma Estação de Tratamento de Esgotos (ETE-UNISC) onde passa todo efluente líquido gerado a partir de cozinhas e sanitários do campus, ocorrendo o tratamento convencional antes de ser encaminhado ao corpo receptor. Juntamente a ETE-UNISC instalou-se um sistema de tratamento multifuncional de baixo custo composto de uma célula de combustível microbiana (CCM) seguida por um Wetland Construído de fluxo vertical (WCFV). E por fim, os testes de toxicidade aguda com o organismo bioindicador Daphnia magna são realizados no Laboratório de Ecotoxicologia na Central Analítica da UNISC.

Figura 1. Localização do Río Grande do Sul no Brasil, e Localização da Cidade de Santa Cruz do Sul e UNISC.

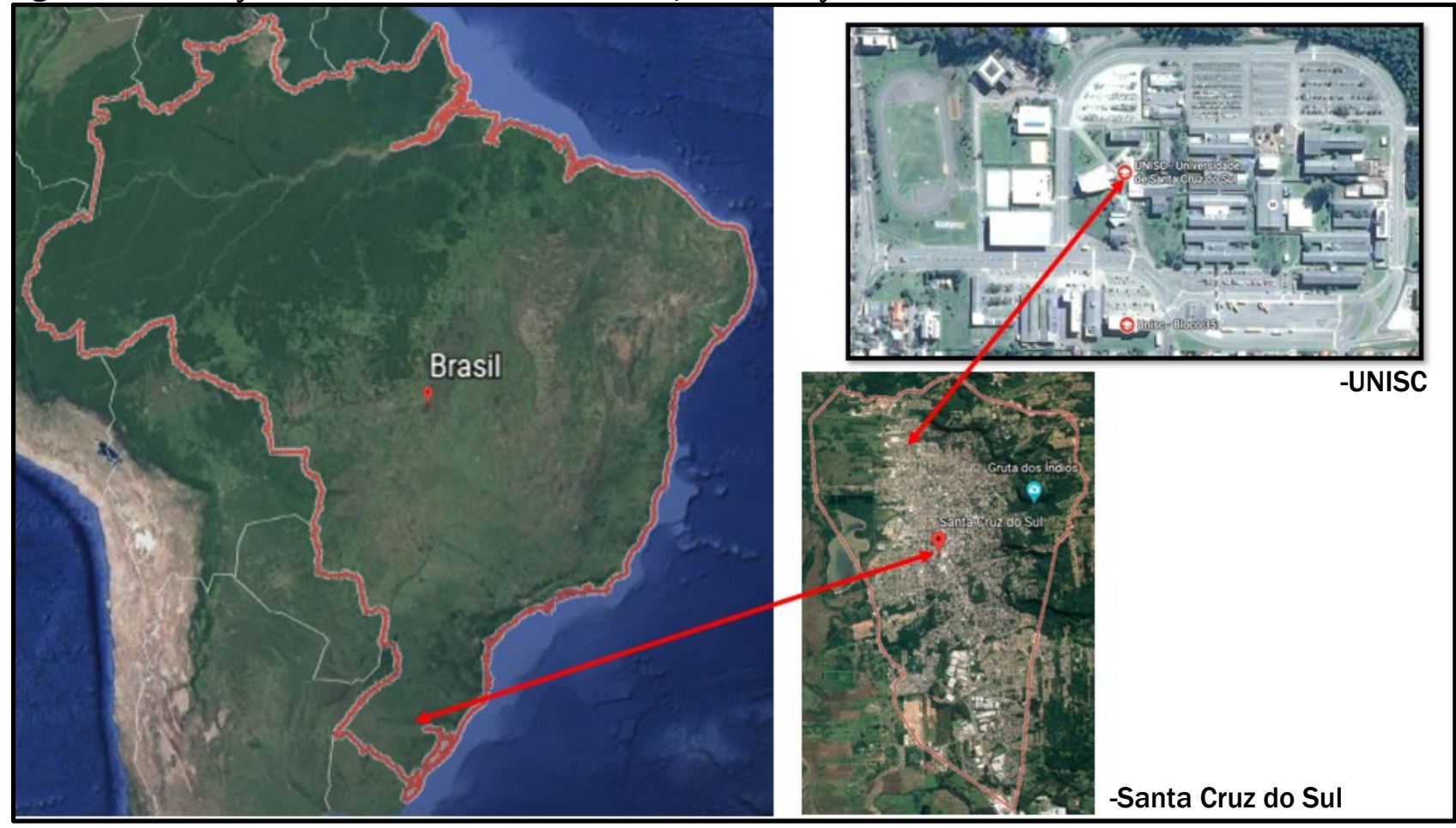

O Hospital Santa Cruz (HSC) encontra-se no centro da cidade, sendo o principal centro de saúde do Vale do Rio Pardo, RS, com cerca de 23 mil metros quadrados de área construída, e com capacidade de atendimento para 232 leitos. Cerca de $150 \mathrm{~m}^{3}$ de águas residuais são gerados diariamente pelos diferentes setores do hospital, dos quais aproximadamente $50 \mathrm{~m}^{3}$ são produzidos pelas máquinas de lavar roupas (LUTTERBECK et al., 2020). 


\subsection{Amostragem}

A coleta do material gerado a partir do setor da lavanderia do HSC foi realizada diretamente no ponto de saída da água das máquinas de lavar, sem qualquer tratamento, antes de serem descartadas na fossa séptica. Os efluentes utilizados nos ensaios de toxicidade foram amostras compostas das diferentes etapas da lavagem. O material coletado foi transportado para a ETE-UNISC onde o sistema de tratamento multifuncional de baixo custo foi alimentado. Esta amostra composta corresponde ao Ponto 1 (P1) do estudo, classificado como efluente bruto, onde foram armazenados cerca de $600 \mathrm{~mL}$ de efluente em garrafa PET higienizada e levadas ao Laboratório de Ecotoxicologia para posteriores testes agudos de toxicidade, e o Ponto 2 (P2) de amostragem do estudo, consiste no efluente da lavanderia do HSC já tratado pelo sistema de célula de combustível microbiana (CCM) e Wetland Construído de fluxo vertical (WCFV).

Ao todo foram realizadas 6 amostragens, as quais aconteceram duas vezes ao mês com intervalo médio de 15 dias, entre os meses de maio a agosto de 2019. Estas foram submetidas ao congelamento logo após a coleta para conservação no laboratório de Ecotoxicologia até a realização dos ensaios conforme a NBR 12713 (ABNT, 2016). Cada ponto amostral foi coletado em duplicata, prevendo a possível não validação dos testes, já que se trata de ensaios com organismos vivos, assim o teste não validado pode ser refeito.

\subsection{Sistema de tratamento multifuncional de baixo custo}

O sistema integrado de baixo custo é composto por duas unidades: CCM + WCFV. Ambas as unidades possuem formato retangular (92 cm de comprimento; $55 \mathrm{~cm}$ de largura; $58,5 \mathrm{~cm}$ de altura) e um volume útil de 200 L (caixas plásticas de polietileno de alta densidade (HDPE) dispostas em um padrão de escada, onde estão instaladas junto a ETE UNISC.

A CCM é composta por cascalho $n^{\circ} 2$ e seixos dividido por lã de vidro (espessura $=10 \mathrm{~cm}$ ) para criar zonas óxicas onde ocorre a disponibilidade de oxigênio, predomínio de algas e cianobactérias, e zonas anóxicas livres de oxigênio. A zona óxica é vegetada pela gramínea Chrysopogon zizanioides (L.) Roberty, e o lado anóxico não constituem plantas. A unidade do WC possui aproximadamente $10 \mathrm{~cm}$ de pedra britada $\mathrm{n}^{\circ} 4(64-100 \mathrm{~mm})$ onde, uma segunda camada de $15 \mathrm{~cm}$ de cascalho $n^{\circ} 2$ foi posicionada na primeira camada. 0 WCFV é vegetado pela macrófita aquática Hymenachne grumosa (Nees) Zuloaga.

Em ambas as unidades, o fluxo de águas residuais de lavanderia foi mantido subsuperficial para minimizar a proliferação de mosquitos e algas, e melhorar a remoção de poluentes. 0 sistema operou em modo de batelada, considerando um tempo de retenção hidráulica (TRH) de 7 dias para cada unidade.

\subsection{Cultivo e manutenção dos organismos-teste}

Acontece uma rotina diária de manutenção dos lotes de cultivo dos organismos-teste $D$. magna (figura 2), que consiste na alimentação utilizando cepas puras da alga verde unicelular Scenedesmus subspicatus, cultivadas em laboratório, e remoção de neonatos (jovens recém-nascidos) para obter um controle de natalidade, e assim poder realizar os testes de sensibilidade (agudo) e toxicidade (agudo), pois os neonatos utilizados nos ensaios precisam ter entre 2 a 26 horas de vida. Esses, por sua vez, são descartados ou podem ser utilizados para 
criar novos lotes de cultivo. Os lotes são constituídos por Becker's com capacidade de $2.000 \mathrm{~mL}$, contendo meio de cultivo específico apresentando $\mathrm{pH}$ entre 7 - 8, cerca de 30 a 40 organismos e alimento. Os lotes de cultivo são acondicionados em incubadora aclimatada na temperatura média de $20{ }^{\circ} \mathrm{C} \pm 2{ }^{\circ} \mathrm{C}$ e fotoperíodo (16 horas claro e 8 horas escuro). Toda e qualquer manipulação dos organismos-teste foi realizada a conforme NBR 12713 (ABNT, 2016).

Figura 2. Organismo teste Daphnia magna. Fonte: MOURA et al. (2017).

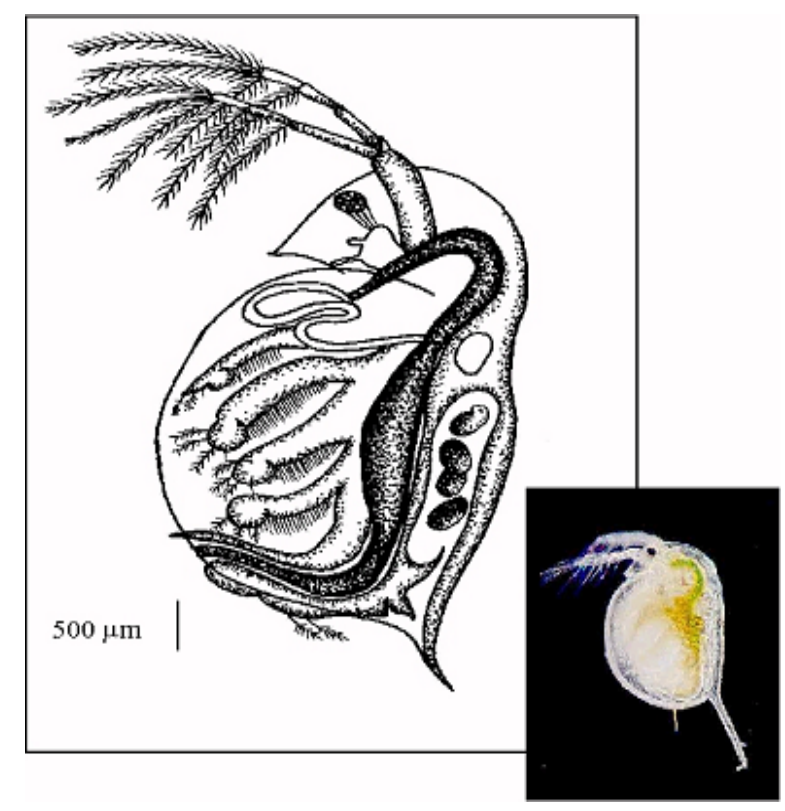

\subsection{Ensaios ecotoxicológicos}

Os testes foram realizados no período de maio a novembro de 2019. Para aferir que os organismos bioindicadores estariam aptos à realização dos testes ecotoxicológicos, primeiramente foram submetidos a testes mensais de sensibilidade (agudo), onde é avaliada a mortalidade e imobilidade dos organismos-teste. 0 teste de sensibilidade consiste em expor neonatos do organismo-teste com idade entre 6 a 24 horas de vida a diferentes concentrações da substância de referência Cloreto de Potássio ( $\left.\mathrm{KCl}, 10 \mathrm{gL}{ }^{-1}\right)$, comumente são utilizadas 5 diluições e mais o controle negativo, sendo as concentrações de $3,0 \mathrm{~mL}-50 \mathrm{~mL}^{-1}, 3,5 \mathrm{~mL}-50 \mathrm{~mL}-1,4,0 \mathrm{~mL}$ $50 \mathrm{~mL}^{-1}, 4,5 \mathrm{~mL}-50 \mathrm{~mL}^{-1}$ e 5,0 mL - $50 \mathrm{~mL}^{-1}$, diluídas em meio de cultivo/diluição. As diluições foram preparadas e distribuídas em dois Becker's de $50 \mathrm{~mL}$ cada, totalizando $25 \mathrm{~mL}$ por Becker onde obtemos duplicatas. Para cada diluição são expostos 20 neonatos, 10 em cada Becker, sendo que o ensaio tem a duração de 24 horas sem a presença de luz. Ao final observa-se quantos organismos estão mortos ou imóveis, os dados são processados e é elaborada a Carta-controle.

0 ensaio ecotoxicológico (agudo) também expõe neonatos com idade entre 6 a 24 horas de vida, porém as diluições são preparadas com as amostras dos efluentes, Bruto (P1) e Tratado (P2), coletados no HSC e CCM/WCFV's, respectivamente. Segue a mesma preparação de materiais do teste de sensibilidade, utilizando 
Becker's de $50 \mathrm{~mL}$ ( $25 \mathrm{~mL}$ por Becker), sendo 5 diluições em duplicata, e mais o controle negativo; $50 \mathrm{~mL}$ - 50 $\mathrm{mL}^{-1}, 25 \mathrm{~mL}-50 \mathrm{~mL}^{-1}, 12,5 \mathrm{~mL}-50 \mathrm{~mL}^{-1}, 6,25 \mathrm{~mL}-50 \mathrm{~mL}^{-1}$ e $3,125 \mathrm{~mL}-50 \mathrm{~mL}^{-1}$. Para cada diluição foram expostos 20 neonatos, $10 \mathrm{em}$ cada Becker, tendo duração de 48 horas sem presença de luz. No final se observa a mortalidade e/ou imobilidade dos organismos-teste, realiza-se a contagem dos mesmos, pois a partir do número total de organismos mortos ou imóveis, no final do experimento, estima-se o nível de toxicidade. A manipulação dos testes também seguiu a NBR 12713 (ABNT, 2016).

\subsection{Análise de dados}

Para a realização dos cálculos estatísticos foram considerados os critérios de mortalidade e imobilidade, sendo que para a execução dos cálculos dos ensaios de sensibilidade (agudo) e ecotoxicológico (agudo), aplicase o programa estatístico Spearman, proposto por Norberg-King (1993). A partir dos cálculos obtidos para os ensaios de sensibilidade, foi possível elaborar a Carta Controle que mostra as faixas de sensibilidade apresentada pelos organismos-teste. E a partir dos resultados das determinações da $\mathrm{CE}(\mathrm{I}) 5048 \mathrm{~h}$ (Concentração Efetiva Inicial Mediana - concentração da amostra no início do ensaio que causa efeito agudo a $50 \%$ dos organismos em $48 \mathrm{~h}$ ) foi utilizada uma escala de toxicidade relativa para o enquadramento das amostras em distintas categorias de toxicidade (tabela 1), proposta por Lobo et al. (2006), e recentemente chancelada por Celente et al. (2020).

Tabela 1. Escala de toxicidade relativa para ensaios agudos com D. magna (retirada de LOBO et al., 2006).

\begin{tabular}{ccc}
\hline Percentil & CE(I)50 48h & Toxicidade relativa \\
\hline $25^{\circ}$ & $<25 \%$ & Extremamente tóxica \\
$50^{\circ}$ & $25-50 \%$ & Altamente tóxica \\
$75^{\circ}$ & $50-75 \%$ & Medianamente tóxica \\
- & $>75 \%$ & Pouco tóxica \\
\hline
\end{tabular}

No processamento da informação, empregou-se a estatística descritiva para a tabulação dos dados e sua ilustração gráfica, como por exemplo, gráfico de barras para visualização e interpretação das medidas de localização e dispersão (média aritmética \pm desvio-padrão, Coeficiente de Variação) (CALLEGARI-JACQUES, 2006).

\section{RESULTADOS E DISCUSSÃO}

A partir dos dados obtidos para os ensaios de sensibilidade do organismo-teste com a substância de referência Cloreto de Potássio $(\mathrm{KCl})$, foi possível elaborar a carta controle (figura 3), a qual apresenta as faixas de sensibilidade para $D$. magna, $C E(I) 5024$ horas $-0,01 \mathrm{mg} \mathrm{L}^{-1}$ a $0,47 \mathrm{mg} \mathrm{L}^{-1}$ para a substância de referência e seus níveis de sensibilidade durante os ensaios. 0 organismo se manteve dentro das faixas, destacando que os resultados demonstraram que os testes de sensibilidade se sustentaram dentro do esperado, o que comprova a estabilidade do cultivo, tornando os organismos aptos a serem utilizados nos ensaios toxicológicos, validando assim as condições de realização dos ensaios de toxicidade. Conforme a NBR 12713 (ABNT, 2016) estabelece, nenhum dos resultados dos ensaios de sensibilidade ultrapassou a faixa de \pm 2 desvios-padrão, evidenciando a 
grande sensibilidade desses organismos e possibilitando, assim, a realização de testes ecotoxicológicos com o organismo bioindicador $D$. magna.

Figura 3. Resultados dos testes de sensibilidade para D. magna (CE(I)50 24h\%).

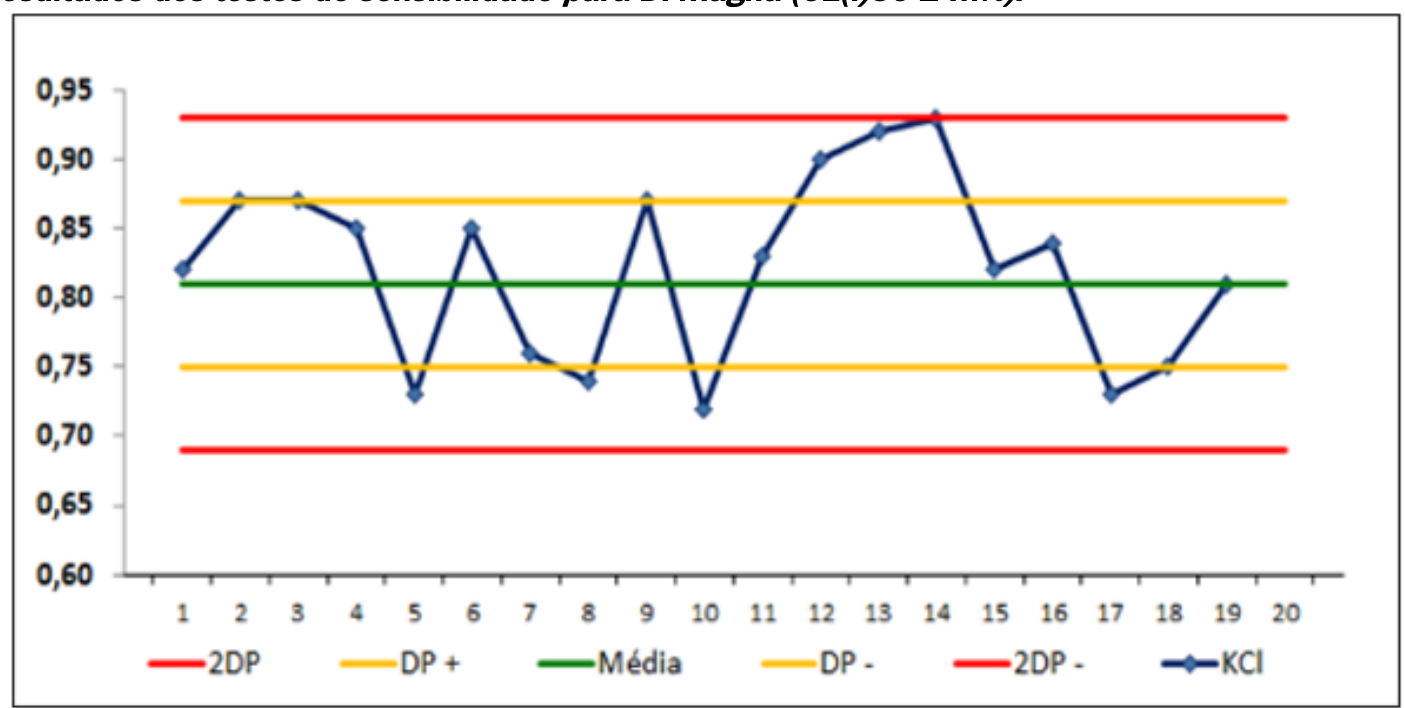

Os pontos azuis indicam a sensibilidade em que os organismos se encontravam no período de desenvolvimento do trabalho. Considerar: $D P=$ desvio-padrão e $2 D P=$ duas vezes o desvio padrão.

Para as amostras de efluentes, dos quais foram 6, os resultados obtidos para os ensaios ecotoxicológicos apresentam-se na tabela 2. Estes mostram que o P1, ponto de coleta correspondente ao efluente bruto, apresentou uma toxicidade aguda média de $\operatorname{CE}(\mathrm{I}) 5048 \mathrm{~h} \%=29,3 \pm 15,5 \%$ (Coeficiente de Variação, $C V=52,8 \%$ ), sendo assim classificado como altamente tóxico para o organismo bioindicador. Em P2, ponto de coleta correspondente ao efluente tratado, apresentou uma toxicidade aguda média de $\operatorname{CE}(\mathrm{I}) 5048 \mathrm{~h} \%=100,0 \pm 0,0 \%$, sendo, deste modo, classificado como não tóxico (figura 4).

Tabela 2. Toxicidade aguda (CE(I)50 48h\%) para D. magna em dois pontos de coleta.

\begin{tabular}{ccc}
\hline Data & P1 - Bruto (\%) & P2 - Tratado (\%) \\
\hline $08 / 05$ & 51.7 & 100 \\
$15 / 05$ & 25.9 & 100 \\
$22 / 05$ & 43.5 & 100 \\
$26 / 05$ & 26.8 & 100 \\
$29 / 05$ & 14.5 & 100 \\
$03 / 07$ & 13.3 & 100
\end{tabular}

P1 - Bruto, saída das máquinas de lavar da lavanderia do hospital. P2 - Tratado (pós sistema de baixo custo multifuncional). 
Figura 4. Toxicidade aguda (CE(I)50 48h\%) média (土 desvio-padrão) para D. magna em dois pontos de coleta.

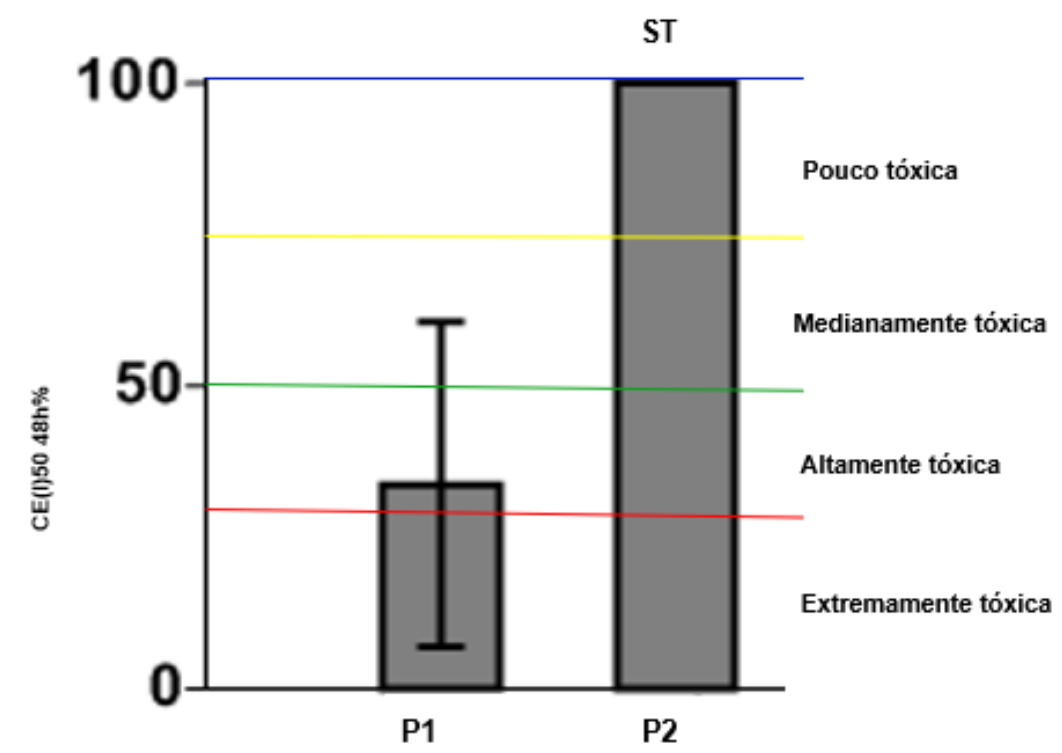

P1: Bruto, efluente da lavanderia do HSC. P2: Tratado (pós CCM+WCFV). ST: Sem Toxicidade.

Verifica-se, portanto, que o ponto de amostragem P1, correspondendo ao efluente bruto da lavanderia do Hospital Santa Cruz, apresentou durante todo o experimento características de um efluente altamente tóxico aos organismos bioindicadores. Esta alta toxicidade observada poderia ser explicada considerando a natureza do efluente, que tem em sua constituição substâncias orgânicas e inorgânicas, sendo que as altas concentrações de produtos químicos, tais como fármacos e seus metabólitos, apresentam menor biodegradabilidade em efluentes oriundos de unidades hospitalares (VERLICCHI et al., 2012; KERN et al., 2015).

Trabalhando com efluentes de lavanderias hospitalares, Zortéa et al. (2018) encontraram resultados de $\mathrm{CE}(\mathrm{I}) 5048 \mathrm{~h} \%$ de $4,4 \%$ a $33,8 \%$ para $D$. magna, indicando características de um efluente altamente tóxico. Estes dados se aproximam aos resultados encontrados neste estudo, onde a $\operatorname{CE}(\mathrm{I}) 50$ 48h ficou entre 13,3\% a 51,7\%, ainda indicando características de um efluente altamente tóxico. Düpont e Lobo (2012) trabalhando com a ETAUNISC, também utilizaram microcrustáceos como organismos bioindicadores para ensaios agudos e crônicos, e concluíram que o efluente doméstico bruto se apresentou altamente tóxico, de forma semelhante aos resultados desta pesquisa. Podemos identificar, portanto, que efluentes de qualquer natureza, e que não sejam submetidos a tratamentos prévios antes de serem lançados em corpos receptores, podem apresentar altos índices de toxicidade para os organismos aquáticos.

0 ponto de amostragem P2, que corresponde ao efluente tratado pelo sistema de tratamento multifuncional de baixo custo, integrado por CCM+WCFV, não apresentou toxicidade em $100 \%$ das amostras, demonstrando a alta eficiência do sistema para a detoxificação de efluentes de lavanderia hospitalar, uma vez que nestes sistemas construídos há um ciclo de autodepuração natural, como os encontrados no ambiente através dos banhados, ocorrendo a fitorremediação por parte das plantas inseridas no sistema e a microbiota que cresce voluntariamente com o decorrer do tempo.

Em um sistema similar composto por CCM-WCFV, Lutterbeck et al. (2020) também encontraram uma toxicidade extremamente aguda para $D$. magna nos ensaios com o efluente não tratado de lavanderia hospitalar. 
Da mesma forma, após o tratamento a toxicidade das águas residuárias reduziram significativamente, já nos primeiros ensaios, corroborando com os resultados aqui encontrados para ambas os efluentes testados.

Os resultados desta pesquisa também coincidem com a pesquisa de Mohr et al. (2015), os quais concluem que os Wetlands construídos (WC's) tem-se mostrado muito efetivos na redução da carga poluidora de efluentes, e sugerem a utilização de sistemas como opções de tratamento, destacando que a utilização da macrófita Hymenachne grumosa como componente principal do sistema foi altamente significativa, representando uma alternativa promissora para a remoção de toxicidade de efluentes domésticos. Colaborando com estes resultados, Costa (2004) também afere em seu trabalho o grande potencial fitorremediador de plantas aquáticas atreladas a WC's, alimentados por efluentes domésticos e industriais. Sabe-se que junto as macrófitas aquáticas muitas vezes estão associadas microalgas nos WC's e Pacheco et al. (2019) afirmam que as microalgas também fazem um excelente papel fitorremediador de águas residuárias. 0 que pode ainda ter auxiliado no processo de detoxificação do sistema avaliado.

Trein et al. (2015) também encontraram resultados expressivos no uso de WC's para tratamento descentralizado de esgotos comerciais e residenciais, sugerindo que quando projetados e operados de maneira adequada, apresentam eficiência compatível com outras tecnologias que promovem o tratamento secundário e terciário. Como o tratamento de efluentes de lavanderia com o uso de eletrooxidação, que se tem mostrado, também, como uma alternativa tecnológica de grande potencial ao promover o tratamento de efluentes de lavanderia hospitalar e esgoto doméstico (MACHADO et al., 2012).

0 desenvolvimento desta pesquisa aponta a importância do tratamento de efluentes antes de serem lançados aos corpos receptores, expostos a impactos ambientais pesados e crescentes, especialmente à poluição por resíduos domésticos e industriais. Contudo, ainda há empresas que não apresentam ou não tem interesse em implantar quaisquer tipos de sistemas de tratamento. Neste contexto, o grupo de pesquisa demonstra que o sistema de tratamento multifuncional de baixo custo é eficiente na remoção de toxicidade para organismos aquáticos, e não demandam alto custo de implantação, operação e manutenção. Ainda, o acompanhamento da eficiência destes sistemas pode ser realizado com organismos bioindicadores como Daphnia magna, cujos protocolos são aceitos nacional e internacionalmente.

\section{CONCLUSÃO}

Os resultados indicaram que $\mathrm{P} 1$, ponto de coleta correspondente ao efluente bruto, apresentou uma toxicidade aguda média de $\operatorname{CE}(\mathrm{I}) 5048 \mathrm{~h} \%=29,3 \pm 15,5 \%$ (Coeficiente de Variação, $\mathrm{CV}=52,8 \%$ ), sendo classificado como altamente tóxico. Já P2, ponto de coleta correspondente ao efluente tratado, apresentou uma toxicidade aguda média de $\operatorname{CE}(\mathrm{I}) 5048 \mathrm{~h} \%=100,0 \pm 0,0 \%$, sendo classificado como não tóxico. Concluímos, desta forma, que o sistema de tratamento multifuncional de baixo custo, integrando o uso de células de combustível microbiana (CCM's) e Wetlands construídos (WC's), para remediação de efluentes de lavanderia hospitalar, foi altamente eficiente, uma vez que houve a completa detoxificação do mesmo, representando uma alternativa promissora para a remoção de toxicidade de efluentes hospitalares. 


\section{REFERÊNCIAS}

ABNT. Associação Brasileira de Normas Técnicas. NBR 12713: Ecotoxicologia aquática-Toxicidade agudaMétodo de ensaio com Daphnia spp (Crustacea, Cladocera). Rio de Janeiro, 2016.

BELDEN, J. Chapter 28 - Introduction to ecotoxicology. In: POPE, C. N. e LIU, J. (Ed.). An Introduction to Interdisciplinary Toxicology: Academic Press, p. 381-393. 2020.

BRENTANO, D. M.; LOBO, E. Biomonitoramento de caráter ecotoxicológico no Vale do Rio Pardo, RS, Brasil. Revista Tecno-Lógica, Santa Cruz do Sul, n. 2, p. 85-95. 2003.

CALLEGARI-JACQUES, S. M. Bioestatística: Princípios e Aplicações. Porto Alegre: Artmed, 255p. 2003.

CALLISTO, M.; GONÇALVES JR, J. F.; MORENO, P. Invertebrados aquáticos como bioindicadores. Navegando o Rio das velhas das Minas aos Gerais, n. 1, p. 1-12. 2005.

COSTA, S. P. Avaliação do potencial de plantas nativas do Brasil no tratamento de esgoto domestico e efluentes industriais em wetlands construidos. 2004. 103 fl. Tese (doutorado) - Universidade Estadual de Campinas, Faculdade de Engenharia Quimica, Campinas, SP. 2004.

<http://www.repositorio.unicamp.br/handle/REPOSIP/266471>.

ARAÚJO, K. S.; ANTONELLI, R., GAYDECZKA, B.; GRANATO, A. C.; MALPASS, G. R. Processos oxidativos avançados: uma revisão de fundamentos e aplicações no tratamento de águas residuais urbanas e efluentes industriais. Ambiente \& Água, v. 11, n. 2, p. 387-401. 2016.

CELENTE, G. S.; COLARES, G. S.; ARAUJO, P. S.; MACHADO, Ê. L.; LOBO, E. A. Acute ecotoxicity and genotoxicity assessment of two wastewater. Environmental Science and Pollution Research, Published online, 2020. https://doi.org/10.1007/s11356-019-07308-y.

DUNBABIN, J. S.; BOWMER, K. H. Potential use of constructed wetlands for treatment of industrial wastewaters containing metals. Science of the Total Environment, 111. n. 2, p. 151-168. 1992.

DÜPONT, A.; LOBO, E. A. Evaluation of the efficiency of the sewage treatment plant from the University of Santa Cruz do Sul (UNISC), RS, Brazil. Acta Limnologica Brasiliensia, 24, n. 2, p. 119-126. 2012.

GUDE, V. G. Wastewater treatment in microbial fuel cells - an overview. Journal of Cleaner Production, 122, p. 287-307. 2016.

LOBO, E. A.; HEINRICH, C. D.; SCHUCH, M.; DÜPONT, A.; COSTA, A. B.; WETZEL, C. E.; ECTOR, L. Índice trófico da qualidade da água: Guia ilustrado para sistemas lóticos subtropicais e temperados brasileiros. EDUNISC: Santa Cruz do Sul. E-Book (www.unisc.br/edunisc). 2016.

LOBO, E. A.; RATHKE, F. S.; BRENTANO, D. M. Ecotoxicologia aplicada: o caso dos produtores de tabaco na bacia hidrográfica do Rio Pardinho, RS, Brasil. p. 41-68. In: ETGES, V. E.; FERREIRA, M. A. F. (Org.). A produção de tabaco: impacto no ecossistema e na saúde humana na região de Santa Cruz do Sul, RS. Santa Cruz do Sul: EDUNISC, 248p. 2006.

LOBO, E. A.; WETZEL, C. E.; SCHUCH, M.; ECTOR, L. Diatomáceas epilíticas como indicadores da qualidade da água em sistemas lóticos subtropicais e temperados brasileiros. EDUNISC: Santa Cruz do Sul. 2014.

LOPES, R. M.; HAUSER-DAVIS, R. A.; OLIVEIRA, M. M.; PIERINI, M. F.; DE SOUZA, C. A. M.; CAVALCANTE, A. L. M.; SANTOS, C. R. D.; COMARÚ, M. W.; DA FONSECA-TINOCA, L. A.Principles of problem-based learning for training and professional practice in ecotoxicology. Science of The Total Environment, v. 702, p. 134809, 2020.

LUTTERBECK, C. A.; MACHADO, Ê. L.; SANCHEZ-BARRIOS, A.; SILVEIRA, E. O.; LAYTON, D.; RIEGER, A.; LOBO, E. A. Toxicity evaluation of hospital laundry wastewaters treated by microbial fuel cells and constructed wetlands. Science of The Total Environment, 2020. https://doi.org/10.1016/j.scitotenv.2020.138816. 
MACHADO, A. I.; BERETTA, M.; FRAGOSO, R.; DUARTE, E. Overview of the state of the art of constructed wetlands for decentralized wastewater management in Brazil. Journal of Environmental Management, v. 187, p. 560-570. 2016. DOI: 10.1016/j.jenvman.2016.11.015.

MACHADO, Ê. L.; LUTTERBECK, C. A.; SCHWAICKHARDT, R. O.; , R.; STRAATMANN, A. KERN, D. I.; ZERWES, F. V.; KIST, L. T.; LOBO, E. A. Eletrooxidação no tratamento de efluentes de lavanderia hospitalar. Caderno de Pesquisa, Santa Cruz do Sul, 24, n. 1, p. 35-46. 2012.

MOHR, G.; DUPONT, A.; MACHADO, E. L.; LOBO, E. A. Avaliação da eficiência da macrófita Hymenachne grumosa como organismo teste, em dois sistemas de tratamento de efluentes, através de ensaios ecotoxicológicos. Revista Jovens Pesquisadores, Santa Cruz do Sul, v. 5, n. 2, p. 02-12. 2015.

MOTA, S. Introdução à Engenharia Ambiental. Rio de Janeiro: ABES, 2000. 416p.

MOURA, D. C.; SOUSA, C. M.; RIEGER, A.; LOBO, E. A. Avaliação da qualidade da água de nascentes na Bacia do Arroio Andréas, RS, Brasil, através de ensaios ecotoxicológicos e genotoxicológicos utilizando o ensaio cometa. $p$. 8-19. In: VIERA, V. B.; PIOVESAN, N. (Org.). Biotecnologia: Aplicação Tecnológica nas Ciências Agrárias e Ambientais, Ciência dos Alimentos e Saúde. Ponta Grossa (PR): Atena, 2017. DOI 10.22533/at.ed.3182806.

NORBERG-KING, T. J. A linear interpolation method for sublethal toxicity: The inhibition concentration (ICp) approach. National Effluent Toxicity Assessment Center Technical Report, 39, p. 3-93. 1993.

PACHECO, M. M.; HOELTZ, M.; BJERK, T. R.; DE SOUZA, M. P.; da SILVA, L. F. F.; GRESSLER, P. D.; MORAES, M. S. A.; LOBO, E. A.; SCHNEIDER, R. C. S. Evaluation of microalgae growth in a mixed-type photobioreactor system for the phycoremediation of wastewater. Journal of Chemical Technology and Biotechnology, 94, n. 10, p. 3102-3110, 2019. Article.

PAZ, M. M,; MENDELSON, A.; MAGDALENO, A.; TORNELLO, C.; BALBIS, N.; MORETTON, J. Evaluation of genotoxicity and toxicity of Buenos Aires City hospital wastewater samples. Journal of the Brazilian Society of Ecotoxicology, v. 1, p. 1-6. 2006.

RAYMUNDO, L. B.; ROCHA, O.; MOREIRA, R. A.; MIGUEL, M.; DAAM, M. A. Sensitivity of tropical cladocerans to chlorpyrifos and other insecticides as compared to their temperate counterparts. Chemosphere, v. 220, p. 937942. 2019.

SHILTON, A. N.; POWELL, N.; GUIEYSSE, B. Plant based phosphorus recovery from wastewater via algae and macrophytes. Current opinion in biotechnology, v. 23. n. 6, p. 884-889. 2012.

TREIN, C. M.; PELISSARI, C.; HOFFMANN, H.; PLATZER, C. J.; SEZERINO, P. Tratamento descentralizado de esgotos de empreendimentos comercial e residencial empregando a ecotecnologia dos wetlandsconstruídos. Ambiente Construído, v. 15, n. 4, p. 351-367. 2015.

VERLICCHI, P.; AL AUKIDY, M.; GALLETTI, A.; PETROVIC, M.; BARCELÓ, D. Hospital effluent: Investigation of the concentrations and distribution of pharmaceuticals and environmental risk assessment. Science of The Total Environment, v. 430, p. 109-118. 2012.

VO, H. N. P.; KOOtTATEP, T.; ChAPAGAIN, S. K.; PANUVATVANICH, A.; POLPRASERT, C.; NGUYEN, T. M. H.; CHAIWONG, C.; NGUYEN, N. L. Removal and monitoring acetaminophen-contaminated hospital wastewater by vertical flow constructed wetland and peroxidase enzymes. Journal of Environmental Management, v. 250, p. 109526. 2019.

ZORTÉA, A. M.; FREIBERGER, V. L., FUZINATTO, C. F. Avaliação toxicológica de efluente de lavanderia hospitalar: toxicidade aguda e crônica com Daphnia magna. Revista Intertox de Toxicologia, Risco Ambiental e Sociedade, v. 11, n. 2, p. 73-85. 2018. 